\title{
Cine-dobradura: o discurso rizomático de Ilha das Flores
}

Thays Renata Poletto

Universidade Tuiuti do ParanálUTP - mestranda 


\section{Resumo}

A autora faz análise do documentário Ilha das Flores, filme que mostra o destino de um tomate, de sua colheita ao lixo. O texto persegue a mesma tentativa de construção e edição do próprio filme. Nele um discurso técnico-científico faz com que uma palavra dita em qualquer trecho do filme leve a uma definição. A análise "brinca" com a construção das afirmações levando em consideração os aspectos da linguagem e considerando o que é aceito em várias outras áreas do conhecimento. Dirigido por Jorge Furtado e realizado no Brasil, em 1989, Ilha das Flores é um convite à reflexão e à diversão. Este texto também.

\section{Palavras-chave}

discurso, rizoma, cinema

\section{Abstract}

The author of this essay analyzes the documentary "Flowers island", a short film that shows the fate of a tomato from the moment it is picked up to the moment it is thrown in a garbage can. This essay follows the same attempt in the building and editing as the film, in which the techno-scientific discourse (narrative) turns each word into its own definition. This analysis "plays" with the statements' construction, taking into consideration metalinguistic aspects and incorporating principles accepted in other areas of knowledge. Directed by Jorge Furtado and made in Brazil, in 1989, "Flowers Island" is an invitation to reflection and entertainment. So is this essay.

\section{Key words}

discourse, rhizome, cinema 
lertado por ruídos diferentes, o navegador saiu de sua cabi-
ne e, encantando, viu um fenômeno raro: o gelo que se
desprendia do iceberg e quase cantava ao cair. De imediato, pensou em registrá-lo, mas logo ponderou consigo mesmo que poderia gravar em vídeo mais tarde, já que estaria ali por muito tempo. O fenômeno não se repetiu mais. E Amir Klink dividiu a lição de não perder oportunidades (e saber considerá-las raras) em um de seus livros (1999).

Não sou o Amir. Nem tenho grande fenômeno diante de mim. É só mais um trabalho de mestrado - escolar, diriam outros como tantos, como quantos. Mas é a oportunidade que me chega à porta. Meus sentidos alertam: não devo perdê-la. E, embora sofra comigo mesma por não saber se o caminho é este, escolho segui-lo.

Escolher é algo que se faz quando se é livre. Ser livre é o sonho de todo adolescente. Nem sei bem se a gente sabe de que quer ser livre nem para que, mas é assim. E foi ainda adolescente que descobri o filme "Ilha das Flores". Numa sala escura, cheirando a novo, com um grupo de outras vinte ou trinta meninas de um colégio católico, fomos levadas a discutir a situação do Brasil. O filme era o mote, mas o que me inquietou foi ver que algo nele era diferente. Olhos inocentes, ávidos pela revolução, não sabia o que era.

Sei agora que é algo que me incomoda, inquieta. Há doze ou treze anos, quando vi o filme (em vídeo) na sala com as colegas, poderia ter dito isso. Mas, talvez pela timidez, talvez por achar que o Brasil não mudaria ou por não saber que era livre, perdi a oportunidade. Volta, agora, a liberdade de escolher o tema. Mesmo tendo sido visto em sala de aula, achei que era uma boa chance 
de falar do incômodo, de rizomatizar o pensamento sobre o filme e, quem sabe, ramificar sentidos. Algo me diz que o fenômeno é raro.

Curta-metragem dirigido por Jorge Furtado, Ilha das Flores fica entre o documentário e a ficção. O filme acompanha a trajetória de um tomate, desde seu plantio até que ele se torne lixo. Utilizando um raciocínio linear, o filme vai apresentando personagens e idéias durante essa trajetória. Cada idéia ou personagem novo surge a partir de palavras ou imagens do texto anterior. O discurso vai do didáticocientífico (sempre fragmentário) ao poético.

O filme recebeu vários prêmios, entre eles: Melhor Curta, Roteiro, Montagem e Prêmio da Crítica, Gramado 89; Urso de Prata, Berlim 90; Prêmio do Público na Competição "No Budget", Hamburgo 91; Prêmio Crítica e Público, Clermont Ferrand 91.

\section{Cine-dobradura}

Incômodo é o que incomoda, embaraça, perturba. Perturbar é causar abalo no espírito, desassossegar. Desassossegar é uma boa palavra para Ihas das Flores - um filme que persegue um tomate, de sua colheita ao seu fim, como lixo, é já um desassossego. Ilha das Flores serve-se da fórmula didática da repetição para estabelecer um discurso científico ${ }^{1}$, justificado, real:

Estamos em Belém Novo, município de Porto Alegre, estado do Rio Grande do Sul, no extremo sul do Brasil. Mais precisamente na latitude 30 graus 12 minutos e 30 segundos sul e longitude 51 graus 11 minutos e 23 segundos oeste (Furtado, 1989)2.

1. O discurso científico é aquele onde o enunciador ausenta-se do enunciado: não há caracterização do responsável pela produção do enunciado, criando o efeito da objetividade. Em llha das Flores, este é um recurso utilizado: não há verbos de dizer (digo, acho, afirmo, penso, creio, por exemplo) na primeira pessoa, as palavras têm sentido denotativo e o texto faz uso da lingua padrão. (Cf. Platão e Fiorin, 1991, pp. 308-316). A mensagem denotada é o próprio analagon e a mensagem conotada é o modo como a sociedade dá a ler, em certa medida, o que se pensa dela. Embora seja este o sentido que o texto quer dar ao filme, há um visão 'conotada' sobre a condição humana (Cf. Barthes, 1984, p. 15).

2. Este texto faz parte do filme llha das Flores. 
O efeito de real ${ }^{3}$, já é estimulado desde o início, quando os primeiros créditos nos garantem: "Este não é um filme de ficção"; "Existe um lugar chamado Ilha das Flores".

Ficção é aquilo que é da arte de imaginar; imaginação é próprio do cinema, de seus filmes. Mas Ilhas das Flores quer apresentar um discurso verossímil, ancorado em dados da realidade (eles são encontrados em todo o filme, desde a localização da primeira cena, descrita acima, até o cartão de Dona Anete, a personagem vendedora de perfumes). Esta ancoragem é parte da caracterização do discurso científico, mas também exerce um controle: guia o olhar, fazendo com que alguns significados da imagem sejam recebidos e outros evitados. Conforme Ernest H. Gombrich,

Nós não tratamos o nosso mundo de forma neutra. Como ocorre com os animais, a sobrevivência do ser humano também depende de coisas e signos reconhecíveis que the são de grande significado. Desta forma, fomos programados de tal maneira a procurarmos objetos que nos são necessários ou perniciosos e cujas configurações nos agradam mais do que outras. Positivamente, a nossa capacidade de reconhecer um objeto parece estar ligada à sua relevância biológica, o que faz com que, nos objetos que nos são importantes do ponto de vista biológico, baste uma vaga semelhança para provocar essa reação. (In: Santaella e Nöth, 1998, p. 42)

Este efeito de real procura-se manter até o final, quando são dados os últimos créditos: "Este filme na verdade foi feito por..." e seguem-se nomes e funções; "A última frase do texto na verdade é..." e segue a fonte do mesmo; "Os temas musicais na verdade foram extraídos..." e segue nome da música e compositor; "Dona Anete na verdade é Ciça Reckziegel"; "Seus familiares na verdade

3. Além dos dados reais citados, ainda podemos lembrar que Bernadet chama a ilusão de verdade de impressão de realidade (grifo do autor), e afirma (comentando sobre a imagem cinematográfica) que esta impressão foi provavelmente a base do grande sucesso do cinema (1986, p. 12). 
são..." e seguem-se os nomes. Os créditos continuam assim, numa forma que rompe com a tradicional "subida de créditos", mas que dá outro significado. A última frase, depois de muitas com "na verdade é", "na verdade fica", "na verdade pertence", dá a certeza ao espectador de que viu um filme que quis comprometer-se em ser real: "O resto é verdade." A repetição da palavra "verdade" diz tanto o que é ficção quanto o que é real.

Repetir é uma forma usada pela didática. A didática é a arte de ensinar. E para ensinar, há que repetir. Repetir para memorizar, aprender: Em Ilha das Flores se retoma tudo, o tempo todo. Não é só a estrutura inicial e a final que se repetem, dando voltas sobre a palavra "verdade", e procurando cumprir a promessa de não ser um filme de ficção, como se o telespectador fosse um aprendiz, como se quem vê não soubesse nada daquilo e tudo fosse inteiramente novo para ele. É quase como se o filme fosse feito para quem nunca viu um ser humano, um japonês ou um tomate. Todas as palavras precisam de esclarecimento. É quase um hipertexto fílmico ${ }^{4}$. A estrutura do filme é repetitiva - como manda a boa didática. Onde houver algo a ser explicado, será explicado, retomado. Imagens e textos. Construções inteiras e sequiências inteiras de imagens. A definição de ser humano, por exemplo, com telencéfalo altamente desenvolvido e polegar opositor é repetida inúmeras vezes. Acompanhando o percurso do tomate desde que é colhido, a organização textual ${ }^{5}$ é repetitiva:

Alguns tomates que o senhor Suzuki trocou por dinheiro com o supermercado e que foram novamente trocados pelo dinheiro que Dona Anete trocou por perfumes foram transformados em molho para a carne do porco (Furtado, 1989).

O tomate plantado pelo senhor Suzuki, trocado por dinheiro como supermercado, trocado pelo dinheiro que

4. O mecanismo de Iha das Flores lembra a navegação por um hipertexto. Quase sugere que estamos vendo alguém que navega: uma citação, uma palavra, um episódio levam a outros.

5. Textual aqui relaciona-se ao texto verbal e não-verbal, palavra e imagem. A referência a texto aqui é a mesma sugerida por Barros $(2001, p .8)$. 
Dona Anete trocou por perfumes extraidos das flores, recusado para o molho do porco, jogado no lixo e recusado pelos porcos, está agora disponivel como alimento para os seres humanos da Ilha das Flores (Furtado, 1989).

A repetição é estrutural: de texto e imagem, mas não é exatamente a mesma imagem e o mesmo texto. No último texto, por exemplo, quando citado, o senhor Suzuki é visto de maneira muito próxima (num plano close-up ou primeiro plano ${ }^{6}$ ). O senhor Suzuki está sorrindo, como que confirmando a afirmação de que plantou os tomates. Nas outras vezes em que aparecera, o personagem não demonstrara essa intimidade com o espectador e só aparece em planos mais abertos. A repetição poderia tornar o discurso monótono, mas o mesmo torna-se rizomático: uma idéia dá suporte ao aparecimento de outra $^{7}$, sem começo ou fim, como raízes que lhe saem pelas horizontalidades, como se tudo estivesse 'entre', na dobra, no meio.

Dobras sobre dobras. Toda uma outra concepção do espaço e do tempo, da relação entre as imagens, emerge dali. O contínuo não é uma linha que se dissolveria em pontos independentes, mas é como um tecido que se divide em pregas, que se decompõe em movimentos curvos. Que acrescenta sempre mais matéria, mais massa. Não pode parar. Tudo escoa e verte numa outra coisa. O princípio da dobra é a curvatura: acrescentar sempre um

6. O primeiro plano ou close-up é o plano da intimidade (cf. Watts, 1990, pp.158159). A escolha de um ou outro plano indica o desejo de dar destaque a uma área particular/dominante do quadro, atraindo o olhar do espectador (cf. Hedgecoe, 1996, pp. 74-75).

7. Como neste texto, onde um parágrafo se liga a outro por uma idéia do parágrafo anterior. A idéia de construi-lo assim está na experiência do aprendiz: aquele que busca no livro, no dicionário, o signíficado das palavras. O aprendiz-espectador de Ilha das Flores parece seguir este destino: buscar em cada palavra sua origem, sua história, seu sentido, num caminho que sempre leva a outra palavra, a uma nova busca, como se entrasse na toca de Deleuze e Guattari: ... a toca (...) comporta às vezes uma nítida distinção entre linha de fuga como corredor de deslocamento e os estratos de reserva ou de habitação (2000, p. 22). Ao mesmo tempo que adquire uma explicação (reserva, habitação), parte em busca de outra palavra, de outro sentido, e outro e mais outro (linha de fuga). 
rodeio, fazendo de todo intervalo o lugar de um novo desdobramento, pagando todo contorno, toda fronteira. O barroco é uma transição. (Parente, 1993, p. 239)

Não se trata de uma simples relação entre duas coisas, mas do lugar onde elas ganham velocidade. $O$ "entrelugar". Seu tecido é a conjunção "e...e...e". Algo acontece entre os elementos, mas não se reduz aos seus termos. Diferente de uma lógica binária, é uma justaposição ilimitada de conjuntos. (Parente, 1993, pp. 238-239)

Dobra é substantivo feminino, diz o dicionário. Quer dizer "prega; vinco; parte dum objeto que faz volta, sobrepondo-se a outra parte; ângulo que formam algumas coisas (Michaelis, 2000, p. 214). São ângulos, dobras que ligam coisas como tomates, porcos, dinheiro e liberdade em Ilha das Flores, e fazem dele uma brincadeira de dobradura fílmica. Cada 'prega' leva a outra. Faz a volta. Cada ângulo forma 'coisas'. De onde brotam novas 'coisas', numa engenharia de

linhas de articulação ou segmentaridade, estratos, territorialidades, mas também linhas de fuga, movimentos de desterritorialização e desestratificação. As velocidades descomparadas de escoamento, conforme estas linhas, acarretam fenômenos de retardamento relativo, de viscosidade ou, ao contrário, de precipitação e ruptura (Deleuze e Guattari, 2000, p. 11).

Um rizoma não começa nem conclui, ele se encontra sempre no meio, entre as coisas, inter-ser, intermezzo. A árvore é filiação, mas o rizoma é aliança, unicamente aliança. A árvore impõe o verbo "ser", mas o rizoma tem como tecido a conjunção "e... e...e..." (...). Entre as coisas não designa uma correlação localizável que vai de uma para outra e reciprocamente, mas uma direção perpendicular, um movimento transversal que as carre- 
ga uma e outra, riacho sem início nem fim, que rói suas duas margens e adquire velocidade no meio. (Deleuze e Guattari, 2000, p. 37)

A ruptura é o corte, a fenda, a abertura. Romper é próprio da poesia. Como um poema, Ilha das Flores rompe repetindo e repete rompendo. A poesia de Ilha das Flores está em sua forma peculiar de repetir, de pôr em relação, de romper e inaugurar novo sentido. A abertura proposta é uma possibilidade de descondicionamento, de ressuscitar um olhar nômade, onde a linha de pensamento é frequientemente rompida e retomada, rompida e retomada, repetidamente. É o processo de repetição e variação de atitudes que dá luz ao cômico ${ }^{8}$. Ilha das Flores traz o caricato do científico e do didático: transformando-se em discurso artístico, ao caminhar de uma função estritamente informativa para a função estético reflexiva (Walty, Fonseca e Cury, 2000). É o artístico que usa a estrutura da correlação, a construção paratática que inaugura outros sentidos. Sobre isto, Haroldo de Campos lembra que

(...) a propensão da escrita chinesa para as construções paratáticas e para os sistemas paralelísticos inspirados numa "lógica da correlação" parece coincidir com os modos de composição da poesia ocidental que, através de aliterações, paronomásias, rimas anagramas, configuram processos relacionais, diagramas internos, constelações de sentido animadas pelas leis das correspondências e analogias. (In: Santaella e Nöth, 1998, p.70)

A analogia é a semelhança de propriedades, é a igualdade incompleta. E assim caminha a relação de correspondência entre o texto e a imagem em Ilha das Flores. Palavra dita, imagem mostrada, num texto que descreve a imagem e é descrito por ela: da redundância à informatividade 9 . Podemos ver também uma "relação bar-

8. O cômico tem necessidade de repetição ou de tipificação (Barthes, 1984, p. 20).

9. Para Kalverkämper a relação imagem-texto pode se dar: 1. a imagem é inferior ao texto; 2. a imagem superior ao texto; 3 . imagem e texto têm a mesma importância (citado em Santaella \& Nöth, 1998, p. 54). 
roca": No barroco, uma coisa exprime a outra, reflete a outra, em total correspondência, em permanente interação (Parente, 1993, p. 239).

Ao nivel da mensagem literal, a palavra responde, de um modo mais ou menos directo, mais ou menos parcial, à questão: o que é isto? Ela ajuda a identificar pura e simplesmente os elementos da cena e a própria cena: trata-se de uma descrição denotada da imagem (descrição muitas vezes parcial), ou, na terminologia de Hjelmslev, de uma operação (oposta à conotação). A função denominativa corresponde bem a uma ancoragem de todos os sentidos possiveis (denotados) do objecto, pelo recurso a uma nomenclatura...(...) a legenda ajuda-me a escolher o bom nível de percepção; ela permite-me acomodar não só o meu olhar, mas ainda a minha intelecção. Ao nível da mensagem "simbólica", a mensagem lingüística guia já não a identificação, mas a interpretação, ela constitui uma espécie de grampo que impede os sentidos conotados de proliferarem quer para regiões demasiado individuais (isto é, ela limita o poder projectivo da imagem), quer para valores disfóricos... (Barthes, 1984, p. 32).

Mesmo os efeitos sonoros usam a relação analógica e a descrição. São exemplos fáceis o som do gongo quando o narrador diz o nome do japonês: Suzuki. O gongo é um instrumento de origem oriental, feito de um disco metálico convexo que se faz vibrar, batendo nele com um bastão. A percussão é de fácil reconhecimento. Neste caso, o nome "Suzuki" aparece em letras brancas sobre um círculo vermelho, cujo fundo é branco. Remete à bandeira do Japão. A circularidade sugerida nesta imagem parece repetir-se na imagem seguinte, quando aparece a figura de um homem com os braços abertos, em um círculo amarelo: é o famoso desenho de Da Vinci (Cianchi, s/d). Outro caso é a apresentação de Dona Anete e sua família. Durante a explicação do que é uma família - explicação de moral 
católica - aparecem fotos em preto e branco: é o álbum da família. As imagens e o áudio caracterizam a família: esta não é qualquer família, é a família de classe média, urbana, com pai e mãe que trabalham, com dois filhos, com algum poder aquisitivo; é a que pode produzir lixo. O som em back ground ${ }^{10}$ que acompanha o texto é uma música muito conhecida utilizada em cerimônias de casamento. São confirmações da narração.

Mas há um outro tipo de uso da música no filme. Acordes atualizados de $O$ Guarani, de Carlos Gomes ${ }^{11}$, juntam o início e o final da Ilha, como a faixa de Moebius ${ }^{12}$. Parece não haver como diferenciar assunto externo ao filme: a condição humana refletida pelos acordes dará conta de qualquer assunto - talvez por isso, ele sirva como mote para a discussão da preservação do meio ambiente, a discussão teológica sobre a existência de Deus (a terceira frase dos créditos diz: "Deus não existe"), da situação do Brasil, do capitalismo ou do futuro da humanidade. À medida em que o filme se aproxima do final, o texto narrado vai sendo envolvido pela música; o volume da música cresce e, num ritmo que se torna mais poético (sustentado pela movimentação da câmera e do uso mais lento das imagens), prolonga-se sobre os créditos.

A música nunca deixou de fazer passar suas linhas de fuga, como outras tantas multiplicidades de transformação, mesmo revertendo seus próprios códigos, os que a estruturam ou a arborificam; por isto a forma musical, até em suas rupturas e proliferações, é comparável à erva daninha, um rizoma. (Deleuze e Guattari, 2000, p. 21)

Confirmar é explicar, re-dizer. Mas o filme também mostra o que não narra e narra o que não mostra. A estrutura do filme

10. Back ground ( $B G)$ é uma expressão utilizada para significar o som com volume abaixo da narração. É utilizado como ambientação (cf. López, 2000, p. 191).

11. Esta música é também conhecida por sua utilização no programa radiofônico " $A$ Voz do Brasil". Produzido pelo governo federal, o programa é obrigatoriamente veiculado por todas as emissoras de rádio brasileiras no horário das 19 horas, de segunda a sexta-feira.

12. O efeito Moebius refere-se à Faixa de Moebius, que dá passagem do interior ao exterior e do exterior ao interior. Esse mundo de relações é a música (Lévy, 1998 , p. 24). 
acostuma ${ }^{13}$, habitua, automatiza (Eco, 1982) o espectador a uma relação entre o verbal e o não-verbal que se dá em duplicata (na medida em que texto e imagem se auto-confirmam). A relação é de concomitância, redundância e informatividade (Santaella e Nöth, 1998, p. 54). É uma função de etapa, mas que, ao invés de banalizar a mensagem, faz a ação avançar ao colocar, na sequiência das mensagens, sentidos que não se encontram na imagem - é a relação complementar entre imagem e texto e a maior carga informativa ora está na imagem ora na palavra (Barthes, 1984, p. 33).

Assim, o efeito de estranhamento (Eco, 1982) é superpotencializado quando uma relação diferente aparece. Depois de explicar as duas características responsáveis por diferenciar o ser humano de outros animais (telencéfalo altamente desenvolvido e polegar opositor), o narrador conta o que o ser humano fez com estas duas habilidades:

O telencéfalo altamente desenvolvido combinando com a capacidade de fazer o movimento de pinça com os dedos deu ao ser humano a possibilidade de realizar um sem número de melhoramentos em seu planeta, entre elas, cultivar tomates (Furtado, 1989).

As imagens que acompanham o texto são de uma mão que colhe uma maçã, de uma figura de maçã mordida que liga com a próxima imagem, a de Adão e Eva. Como numa colagem, rapidamente vão aparecendo outras figuras, como a Torre de Babel, as pirâmides do Egito, o Fórum Romano e várias construções, - citação de outros textos, acompanhados por sons que lembram tanto construção como demolição. É uma retrospectiva histórica, de cunho católico, da história do homem. Aqui o paradigma é palimpsesto: na estrutura alegórica, um texto é lido através de outro. A arte existe

13. Espaço dinâmico em mutação permanente, sem centro nem ponto fixo. Essa incerteza gera uma forma de ambigüidade, de intervalo, de lacuna, enfim, de diferença. As coisas são intervalos - estão sempre no meio. É a partir desse campo, na interseç̧ão de múltiplos olhares, que as formas tomam forma. (Parente, 1993, p. 240) 
como uma trama de referências, não necessariamente localizada na forma, medium ou local (Parente, 1993, p. 240).

Quando a narração chega em "entre elas" há uma suspensão da narrativa, uma pausa no tempo e um som diferente invade a emissão. Adia-se a narração para que a imagem tome seu valor: é a imagem da bomba atômica, explodindo num cogumelo de luz, numa intertextualidade em que a situação da explosão é lembrada ${ }^{14}$. A suspensão carrega a emoção, mas o grau de significância tornou -se maior porque a estrutura foi rompida: a continuação do texto "entre elas" é "cultivar tomates". A situação do espectador aqui é semelhante à do leitor da poesia concreta: o desassossego imposto traz a ampliação do campo de interpretação, de sentidos e novas experiências. As várias disposições das palavras no papel faziam com que os olhos dos leitores ficassem à deriva, procurando um sentido lógico para as mensagens caóticas (Marques, 2000). Em seguida, depois da bomba e mudança de expectativa, voltamos a ter uma mão que colhe um tomate. É o mesmo gesto que, no início da frase, mostrava uma mão a colher uma maçã. Mas a mão que colhe a maçã e a mão que colhe o tomate fazem coisas distintas.

O tomate é o fruto do tomateiro. Serve como alimento. A maçã é fruto da macieira. Também serve como alimento. Mas a maçã carrega consigo outra simbologia: é a fruta proibida da árvore bíblica do conhecimento (cf. Gênesis 3,3$)^{15}$. Comendo dela, saber-seia sobre o bem e sobre o mal, a vida e a morte. Então, colher a maçã está relacionado às duas habilidades humanas (o telencéfalo altamen-

14. A ruptura estrutural da relaçāo imagem-som-palavra e o hiato entre uma narração e outra evocam fortemente outras imagens mentais do mesmo episódio. Pesquisas neurofisiológicas também mostraram que imagens mentais ativam, no cérebro, os mesmos padrões de excitação neuronal (do córtex visual) que a visāo real e essas regiōes do cérebro ativadas no processo visual são outras do que aquelas ativadas por conceitos abstratos. Por outro lado, operações simbólicas também devem ter, ao mesmo tempo, um papel na evocação de imagens mentais, pois a ativação de regiões do cérebro que, em outros casos, ocorre no processamento lingüístico, também pode ser observada (Santaella e Nöth, 1998, p. 32, citando Hagen, Giselher).

15. A maçā também tem o significado da fertilidade, do amor, e é ambivalente podendo significar a vida ou a morte. Para conhecer outros significados, ver Lurker (1997). 
te desenvolvido e o polegar opositor), às construções que se seguem em forma de imagens e à bomba atômica (comendo a maçã é capaz da escolha entre o bem e o mal, é capaz de construir a bomba, de programar a morte). A conotação aqui tem função regularizadora e preserva o jogo irracional da projeção-identificação:

na maioria das vezes, o texto não faz senão amplificar um conjunto de conotações já incluídas na fotografia; mas por vezes, também o texto produz (inventa) um significado inteiramente novo e que é de certo modo projectado retroactivamente na imagem... (...) Por vezes também a palavra pode ir até contradizer a imagem de maneira a produzir uma conotação compensatória..." (Barthes, 1984, p. 22)

A morte é o fim da vida, da existência. Mesmo com o telencéfalo altamente desenvolvido e o polegar opositor, é próprio do ser humano morrer. A expressão da morte é trazida em cenas do holocausto judeu, trazidas por platôs interligados: senhor Suzuki troca seus tomates no supermercado por dinheiro; o dinheiro foi inventado por Giges, rei da Lídia, no século III antes de Cristo; Cristo era um judeu. As imagens de notas de dinheiro vão sendo coladas, umas sobre as outras, explicando o dinheiro. Então se fala de Cristo, que aparece cruxificado. Em primeiríssimo plano ${ }^{16}$, a câmera nos leva até a placa sobre a cruz: "INRI", rei dos judeus. O texto segue explicando que judeus possuem o telencéfalo altamente desenvolvido e o polegar opositor. Esquálidos, em imagens em preto e branco ${ }^{17}$, que também ancoram o texto, os judeus são mostrados em pé, vivos, e logo após, corpos de judeus mortos. Duas pilhas são vistas. Uma quando um corpo é jogado e se focalizam outros ao lado, também muito magros. E outra, maior, mais ao longe, quando o narrador, numa tomada

16. O primeiríssimo plano traz a sensação de intimidade e a confrontação fica ainda mais forte, sendo um recurso utilizado para causar impacto (cf. Watts, 1990, pp. 158-159).

17. As imagens em preto e branco dão o sentido de real na medida em que sugerem fatos históricos, já ocorridos, realmente. 
do discurso lógico (se A é B e B é D, então A é D), conclui: "são portanto seres humanos". Estas imagens constituem nova intertextualidade no tex to e novo rompimento com a relação anteriormente estabelecida na articulação verbal e não-verbal. Há um extrapolamento do sentido: o que se vê vai além do que se está dizendo. Aqui o texto parece não ser feito de unidades, mas de dimensões, ou antes de direções movediças. Ele não tem começo nem fim, mas sempre um meio pelo qual ele cresce e transborda." (Deleuze e Guattari, 2000, p. 32). O transbordamento é necessário para explicar o que é um judeu. A opção é pelo que poderíamos chamar de estereótipo do judeu: a imagem mais conhecida deste povo, é de seu holocausto. Mas seria necessário dizer o que é um judeu para falar de um tomate? Aqui um novo rizoma-pergunta nasce para o espectador: se são seres humanos por que não são tratados como seres humanos?

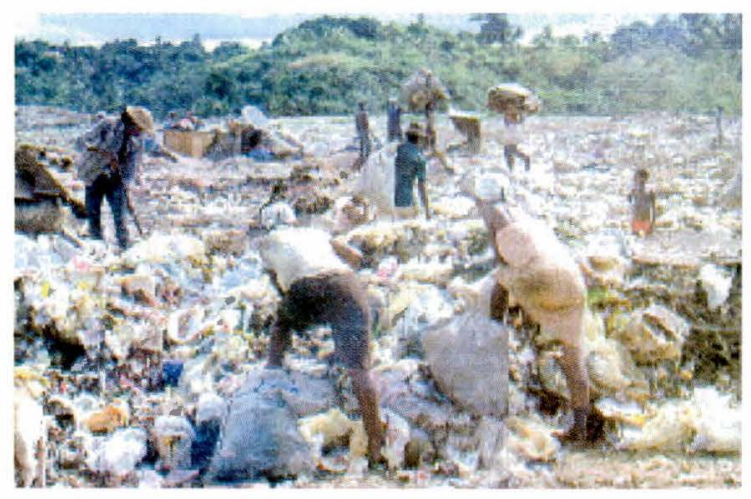

A pergunta é uma frase com que se interroga. A interrogação sobre o tratamento dispensado a estes seres humanos é também a mesma com que Ilha das Flores se encerra: então, por que os seres humanos da Ilha das Flores só podem escolher sua comida no lixo depois que os porcos escolheram? A pergunta não é feita pelo narrador, mas nasce de sua fala:

O tomate plantado pelo senhor Suzuki, trocado por dinheiro como supermercado, trocado pelo dinheiro que 
Dona Anete trocou por perfumes extraídos das flores, recusado para o molho do porco, jogado no lixo e recusado pelos porcos, está agora disponível como alimento para os seres humanos da Ilha das Flores (Furtado, 1989).

O espectador é obrigado a perguntar-se por quê e o narrador, "sentindo seu questionamento", responde: O que coloca os seres humanos da Ilha das Flores depois dos porcos na prioridade da escolha de alimentos é o fato de não terem dinheiro nem dono (Furtado, 1989). Há uma conversa antecipada pelo narrador, há um "inter-colóquio" 18 " pressentido no texto, estimulado pela imagem. Poderíamos dizer que é interativo, se a palavra já não denunciasse: ativo é próprio de quem age e aqui o espectador continua espectador, sentado em sua poltrona. Podemos perceber, no entanto, que há um diálogo intuído. Um diálogo que precisa de mais calor que o diálogo didático-científico: então o ritmo se reduz e o poético toma seu lugar, numa citação de Cecília Meireles: Liberdade é uma palavra que o sonho humano alimenta, que não há ninguém que explique e ninguém que não entenda ${ }^{19}$. E não é gratuito terminar tão poético um diálogo que começa tão preso a definições técnicas e a dados da realidade, pois sonho e liberdade são filhos da poesia. É poético o verbo alimentar aqui: não é só da fome física que se fala, mas é a fome do sonho, da liberdade. E é liberdade sobre o uso do discurso científico, dobrado tantas vezes sobre si mesmo, que acaba dando vida a um poético-rizomático-criativo. Libertário.

18. Inter no sentido de interior, interno.

19. O original de Cecilia Meireles traz o texto: Liberdade - essa palavra/ que o sonho humano alimenta:/ que não há ninguém que explique,/ nem ninguém que nāo entenda. Este trecho faz parte do poema Romance XXIV ou da Bandeira da Inconfidência (Meireles, 1989, p.108). 


\section{Bibliografia}

BARROS, D. L. P. de. 2001. Teoria Semiótica do Texto. 4.ed. São Paulo: Ática.

BARTHES, R. 1984. A câmara clara. Rio de Janeiro: Nova Fronteira. BÍBLIA SAGRADA. 1992. Trad. João Ferreira de Almeida. Rio de Janeiro: Imprensa Bíblica Brasileira.

BERNADET, J-C. 1986. O que é cinema. 8.ed. São Paulo: Brasiliense.

CAMPOS, H. de. (org.). 1977. Ideograma. São Paulo: Cultrix.

CESAR, N. 2001. Direção de arte em propaganda. 3.ed. São Paulo: Futura.

CIANCHI, M. s/d. Le Macchine di Leonardo da Vinci. Milano: Becocci Editore.

COELHO NETTO, J. T. 1990. Semiótica, informação e comunicação - diagrama da teoria do signo. 3.ed. São Paulo: Perspectiva.

DELEUZE, G.; GUATTARI, F. 2000. Mil Platôs. São Paulo: Editora 34.

ECO, U. 1982. Tratado Geral de Semiótica. São Paulo: Perspectiva.

HEDGECOE, J. Guia completo de fotografia. 1996. Trad. Luis Eduardo Machado. São Paulo: Martins Fontes.

FURTADO, J. Ilha das Flores. 1989. Porto Alegre: Casa de Cinema, 13 min. Filme.

KLINK, A. 1999. Cem dias entre céu e mar. São Paulo: Companhia das Letras.

LÉVY, Pierre. 1998. O que é o virtual. São Paulo: Editora 34.

LÓPEZ, V. J. I. 2000. Manual urgente para radialistas apasionados. 2.ed. Quito: Artes Gráficas Silva.

LURKER, M. 1997. Dicionário de Simbologia. Trad. Mário Krauss e Vera Barkow. São Paulo: Martins Fontes.

MARQUES, A .2000. Poesia Digital: passagens entre o tecnopoético e o tecno-lógico. In: Geraes - Revista de Comunicação Social - Publicação do Depto de Comunicação Social e do Programa de Pós-Graduação em Comunicação Social da FAFICH/ UFMG. n. 51 . 
MEIRELES, C. 1989. O Romanceiro da Inconfidência. 12.ed. Rio de Janeiro: Nova Fronteira.

MICHAELIS. 2000. Minidicionário escolar da língua portuguesa. São Paulo: Melhoramentos.

SANTAELLA, L.; NÖTH, W. 1998. Imagem-cognição, semiótica, mídia. São Paulo: Iluminuras, pp. 13-84.

PARENTE, A. (org.). 1993. Imagem Máquina - a era das tecnologias do virtual. Rio de Janeiro: Editora 34.

PLATÃO, F. P.; FIORIN, J. L. 1991. Para entender o texto - leitura e redação. 2.ed. São Paulo: Ática.

WALTY, I.;FONSECA, M; CURY, M. Z. 2000. Palavra e Imagem: leituras cruzadas. Belo Horizonte: Autêntica.

WATTS, H. 1990. On Camera: o curso de produção de filme e vídeo da $B B C$. São Paulo: Summus. 